\title{
Analysis of AC3-33 gene expression in multiple organ cancer and adjacent normal tissue by RNA in situ hybridization
}

\author{
FEN HU ${ }^{1}$, SHAOQING YANG ${ }^{1}$, SHAOBO LV ${ }^{1}$, YAN PENG ${ }^{1}$, LIJUN MENG ${ }^{2}$, LIXIA GOU ${ }^{1}$ and XIUJUN ZHANG ${ }^{1}$ \\ ${ }^{1}$ College of Life Sciences, College of Psychology, Hebei United University, Tangshan; \\ ${ }^{2}$ Department of Environment and Chemical Engineering, Tangshan College, Tangshan, Hebei 063000, P.R. China
}

Received June 11, 2014; Accepted February 23, 2015

DOI: $10.3892 / \mathrm{ol} .2015 .3112$

\begin{abstract}
The AC3-33 gene encodes a secretory protein that can inhibit Elk1 transcriptional activity via the ERK1/2 pathway. In the current study, in situ RNA hybridization was used to detect the AC3-33 gene expression in multiple organ cancer and cancer-adjacent normal tissue. The results showed that the expression level of AC3-33 varies across different tissues. AC3-33 exhibited positive expression in squamous cell carcinoma of the esophagus, adenocarcinoma of the rectum, hepatocellular carcinoma, squamous cell carcinoma (SCC) of the lung, cancer-adjacent normal hepatic tissue, clear cell carcinoma of the kidney, invasive ductal carcinoma of the breast, SCC of the uterine cervix and cancer-adjacent normal kidney tissue. Negative expression of AC3-33 was observed in adenocarcinoma of the stomach and colon, cancer-adjacent normal esophageal tissue, cancer-adjacent normal gastric tissue, cancer-adjacent normal colon tissue, cancer-adjacent normal rectal tissue, serous adenocarcinoma of the ovary and cancer-adjacent normal ovarian tissue. However, the expression of $A C 3-33$ in cancer adjacent normal breast tissue was partially positive. In conclusion, the $A C 3-33$ gene does exhibit positive expression in certain carcinomas, which may indicate that $A C 3-33$ has a significant involvement in the development and progression of these carcinomas.
\end{abstract}

\section{Introduction}

AC3-33 (GenBank name: C3orf33, accession no. FLJ31139), also known as chromosome 3 open reading frame 33 , encodes a classical secretory protein with a predicted molecular mass of $29.3 \mathrm{kDa}(1)$. Transcription factor activator protein-1 (AP-1) is crucial in the regulation of cellular proliferation, transformation and death (2). Using a dual-luciferase reporter assay system, our previous study found that AC3-33

Correspondence to: Professor Xiujun Zhang, College of Life Sciences, College of Psychology, Hebei United University, 57 Jianshenan Road, Tangshan, Hebei 063000, P.R. China

E-mail: xiujunzhang66@126.com

Key words: AC3-33, RNA in situ hybridization, cancer significantly inhibited AP-1 transcriptional activity. Further investigation indicated that AC3-33 significantly inhibited the transcriptional activity of Elk1 and c-jun, but not of c-fos; additionally, AC3-33 significantly inhibits Elk1 transcriptional activity via the extracellular-signal-regulated kinases $1 / 2 /$ mitogen-activated protein kinases pathway. This occurs via disruption of ERK1/2 MAPK pathway (3). AC3-33 is highly expressed in a number of tissues, including the adrenal glands and cervix, and expression is comparatively significantly reduced in the human leukemia cell lines, K562 and KG1a (4). However, the expression of AC3-33 in multiple organ tumors and cancer-adjacent normal tissue remains to be elucidated.

In the present study, RNA in situ hybridization was used to detect the AC3-33 gene expression in multiple organ tumors and cancer-adjacent normal tissue. An improved understanding of the expression of $A C 3$-33 may offer more information as to the role of $A C 3-33$ in the pathological process of tumorigenesis, which may subsequently provide a new insight into $A C 3-33$ and its potential applications in the treatment and diagnosis of human disease.

\section{Materials and methods}

Tissue microarray. Tissue microarray was purchased from Chaoying Biotechnology (Xian, China; MCN602). Specimens for microarray were obtained from a total of 56 cases of multiple organ tumors and adjacent normal tissue. This included 10 organ types (esophagus, stomach, colon, rectum, liver, lung, kidney, breast, uterine cervix, ovary), three tissue cores for cancerous tissue, three adjacent normal tissue cores for each organ and a single specimen per case. For all specimens, details of age, gender, organ, pathological diagnosis, clinical grade, TNM classification, clinical stage, specimen type and results were recorded. This study was approved by the ethics committee of Hebei United University (Tangshan, China).

Preparation of digoxigenin-labeled probes for RNA in situ hybridization. Sense and anti-sense probes that matched the AC3-33 corresponding sequence were: Anti-sense, TATAA*GTTCTCTGAACTTCAGTATT AAGGAGCAGTTGTTCATGTTGTCTTTC-DIG; and sense, GAAATG*TTAAACTACGTGGACGATTA 
Table I. The association between AC3-33 expression and multiple organ tumors and cancer adjacent normal tissue.

\begin{tabular}{|c|c|c|c|c|}
\hline Organ & Pathological diagnosis & Tumors, $\mathrm{n}$ & $\begin{array}{l}\text { AC3-33 mRNA-positive } \\
\text { tumors }(+/+/++)\end{array}$ & $\begin{array}{c}\text { AC3-33 mRNA-negative } \\
\text { tumors }\end{array}$ \\
\hline \multirow[t]{2}{*}{ Esophagus } & Squamous cell carcinoma & 3 & $3(1 / 2 / 0)$ & 0 \\
\hline & Cancer adjacent normal esophageal tissue & 3 & 0 & 3 \\
\hline \multirow[t]{2}{*}{ Stomach } & Adenocarcinoma & 3 & 0 & 3 \\
\hline & Cancer adjacent normal gastric tissue & 3 & 0 & 3 \\
\hline \multirow[t]{2}{*}{ Colon } & Adenocarcinoma & 3 & 0 & 3 \\
\hline & Cancer adjacent normal colon tissue & 3 & 0 & 3 \\
\hline \multirow[t]{2}{*}{ Rectum } & Adenocarcinoma & 3 & $3(1 / 2 / 0)$ & 0 \\
\hline & Cancer adjacent normal rectal tissue & 3 & 0 & 3 \\
\hline \multirow[t]{2}{*}{ Liver } & Hepatocellular carcinoma & 3 & $3(0 / 3 / 0)$ & 0 \\
\hline & Cancer adjacent normal hepatic tissue & 3 & $3(0 / 0 / 3)$ & 0 \\
\hline \multirow[t]{2}{*}{ Lung } & Squamous cell carcinoma & 3 & $3(1 / 2 / 0)$ & 0 \\
\hline & Cancer adjacent normal lung tissue & 1 & $1(0 / 1 / 0)$ & 0 \\
\hline \multirow[t]{2}{*}{ Kidney } & Clear cell carcinoma & 3 & $3(0 / 2 / 1)$ & 0 \\
\hline & Cancer adjacent normal kidney tissue & 3 & $3(0 / 3 / 1)$ & 0 \\
\hline \multirow[t]{2}{*}{ Breast } & Invasive ductal carcinoma & 3 & $3(0 / 2 / 1)$ & 0 \\
\hline & Cancer adjacent normal breast tissue & 4 & $3(1 / 2 / 0)$ & 1 \\
\hline Uterine cervix & Squamous cell carcinoma & 3 & $3(0 / 2 / 1)$ & 0 \\
\hline \multirow[t]{2}{*}{ Ovary } & Serous adenocarcinoma & 3 & 0 & 3 \\
\hline & Cancer adjacent normal ovarian tissue & 3 & 0 & 3 \\
\hline
\end{tabular}

Staining was scored using a $0-3+$ scale. 0 , no staining; $1+, 2+$ and $3+$ indicate increased intensity of the staining. Sub-regions excluding necrosis, macrophages and infiltrated neutrophils and lymphocytes were selected and scored. The intensity score for an array spot is the average of all its sub-regions.

CGCCGAATAACTGAGAATGGTTTA-DIG. The asterisk indicates that the 3 ' terminal was labeled with digoxigenin. All probes were synthesized by Sangon Biotech (Shanghai, China).

RNA in situ hybridization. Hybridization procedures were performed in this study as described. Hybridization conditions were as follows: Anti-sense or sense probe concentration, 20 ng/ul; anti-digoxigenin antibody (catalog no. ab76907; Abcam, Cambridge, UK) dilution, 1:500; washing temperature, room temperature; dyeing temperature, $37^{\circ} \mathrm{C}$; dyeing time, $2 \mathrm{~h}$. Deparaffinized sections were mounted on Denhardt-coated glass slides (D2532; Sigma Aldrich, St. Louis, MO, USA) and treated with pepsin $(0.25 \mathrm{mg} / \mathrm{ml}$ in diethylpyrocarbonate $\mathrm{H}_{2} \mathrm{O}-\mathrm{HCl}$ ) for $30 \mathrm{~min}$ in a $37^{\circ} \mathrm{C}$ water bath. The treated sections were then processed for in situ hybridization at $42-47^{\circ} \mathrm{C}$ for $24 \mathrm{~h}$. The hybridization mixture contained the labeled oligonucleotide probe, $50 \%$ formamide, $10 \mathrm{mmol} / 1 \mathrm{Tris}-\mathrm{HCl}, 1 \mathrm{mmol} / \mathrm{l}$ vanadyl-ribonucleoside complex (Sigma-Aldrich; catalog no. 94740 ), $1 \mathrm{mmol} / 1$ cetrimonium bromide (Sigma-Aldrich; catalog no. 855820, pH 7.0), $0.15 \mathrm{~mol} / 1 \mathrm{NaCl}, 1 \mathrm{mmol} / 1$ EDTA (pH 7.0), 1xDenhardt's mixture and 10\% dextran sulfate. Following hybridization, the slides were washed three times, $30 \mathrm{~min}$ each time, in $0.1 \mathrm{~mol} / 1$ Tris buffered saline (TBS) at $47^{\circ} \mathrm{C}$, and subsequently treated with TBS $(100 \mathrm{mmol} / \mathrm{l}$ Tris, $\mathrm{pH} 7.5,150 \mathrm{mmol} / 1 \mathrm{NaCl})$ containing $1 \%$ blocking reagent (Roche Diagnostics, Shanghai, China) and $0.03 \%$ Triton X-100 for $30 \mathrm{~min}$ at room temperature and incubated for $30 \mathrm{~min}$ with antidioxigenin alkaline phosphatase-conjugated antibodies (Roche Diagnostics) diluted at 1:4000 in TBS containing $0.03 \%$ Triton X-100 and a 1\% blocking reagent. After washing three times in TBS and $0.05 \%$ Tween, 15 min each time, the slides were rinsed in a diammonimum phosphate (DAP) buffer (100 mmol/1 Tris, pH 9.5, 100 mmol/1 NaCl, 50 mmol/l $\mathrm{MgCl}_{2}$ ) and subsequently hybridization signals were visualized using nitroblue tetrazolium and 5-brom-4-chlor-3-indolyl phosphate as substrates [DAP in 10\% polyvinyl alcohol (Sigma-Aldrich; catalog no. 341584)]. Positive expression was determined to be $1+, 2+$ and $3+$ staining, and negative expression was observed as no staining.

\section{Results}

The association between AC3-33 expression and multiple pathological cell types. The AC3-33 gene expression in multiple organ and cancer-adjacent normal tissue was detected by RNA in situ hybridization. As shown in Table I and Fig. 1, the expression level of $A C 3-33$ varies between the different tissues. The expression of $A C 3-33$ is positive in squamous cell carcinoma (SCC) of the esophagus and adenocarcinoma of the rectum, but is negative in cancer-adjacent normal esophageal tissue and cancer-adjacent normal rectal tissue. AC3-33 exhibits positive expression in hepatocellular 


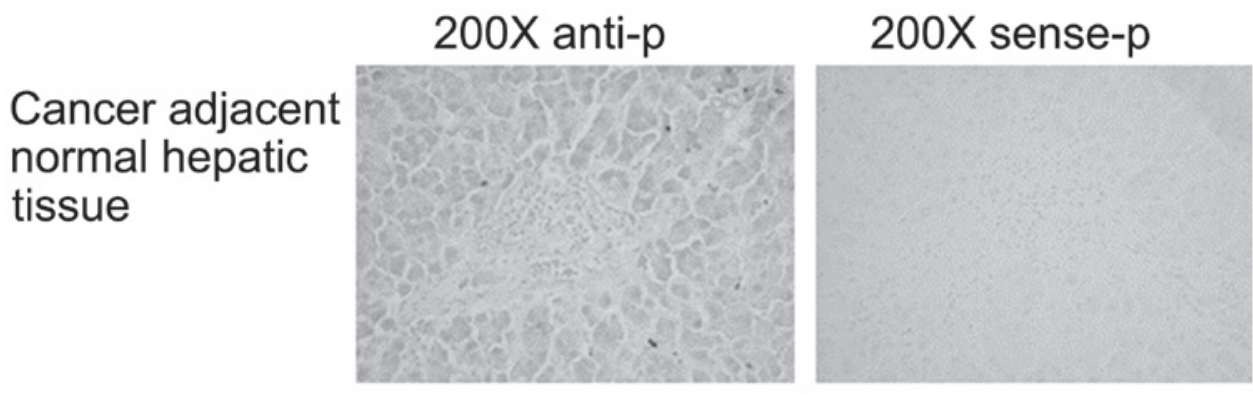

\section{Clear cell carcinoma of kidney}
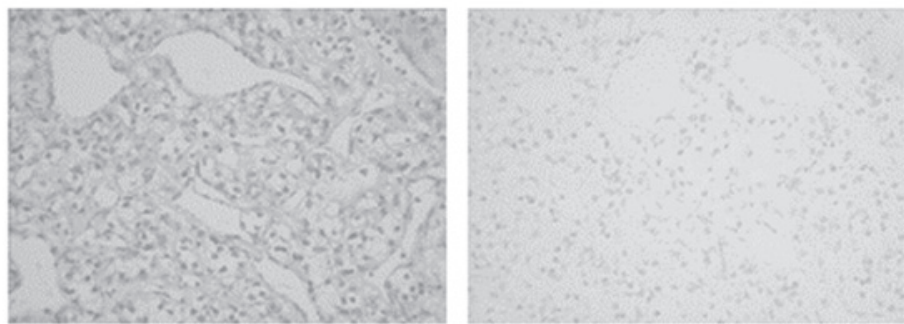

\section{Squamous cell carcinoma of uterine cervix}
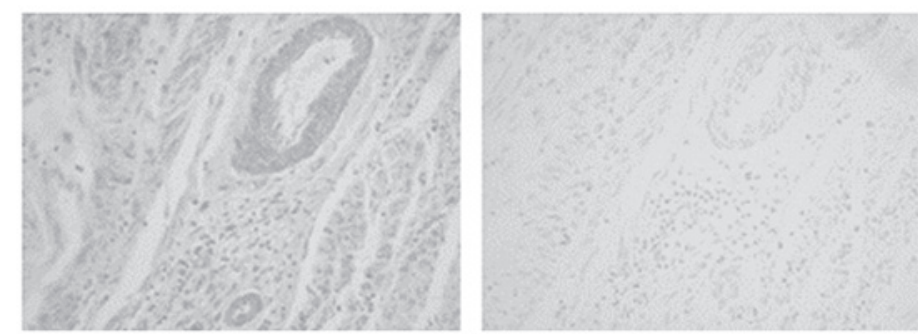

Figure 1. Reflectance in situ hybridization showing expression of AC3-33 in different tumor tissue samples. AC3-33 in cancer adjacent normal hepatic tissue, clear cell carcinoma of the kidney and squamous cell carcinoma of uterine cervix.

carcinoma and cancer-adjacent normal hepatic tissue, clear cell carcinoma of the kidney and cancer-adjacent normal kidney tissue. Negative $A C 3-33$ expression was observed for adenocarcinoma of the stomach and cancer-adjacent normal gastric tissue, adenocarcinoma of the colon and cancer-adjacent normal colon tissue, serous adenocarcinoma of the ovary and cancer-adjacent normal ovarian tissue. AC3-33 exhibited positive expression in squamous cell carcinoma of the lung, invasive ductal carcinoma of the breast and squamous cell carcinoma of the uterine cervix. However, the expression of AC3-33 in cancer-adjacent normal breast tissue is partially positive.

\section{Discussion}

With $>300,000$ new cases per year, cancer of the esophagus, predominantly SCC, is one of the 10 most frequently diagnosed tumor types (5). Esophageal cancer often occurs in developing countries, and the incidence is greatly different between different regions (5). The development of molecular oncology in the last decade has provided much information with regard to genetic abnormalities in cancer, and the clinical characteristics of cancer patients can now be predicted on the basis of these genetic abnormalities. Expression of N-myc (6), int-2 (7), cyclin D1 (8) and p53 (9) may be useful markers for predicting the outcome and distant organ metastasis in patients with SCC of the esophagus. The current study also found that AC3-33 exhibits positive expression in esophagal SCC, but negative expression in cancer-adjacent normal esophageal tissue. These results indicate that $A C 3-33$ may be a novel prognostic factor.
Colorectal cancer (also known as colon cancer, rectal cancer, bowel cancer or colorectal adenocarcinoma) is a cancer due to uncontrolled cell growth in the colon or rectum, or in the appendix (10). Genetic analysis has shown that colon and rectal tumors are genetically the same cancer (11). Although the prognosis of rectal adenocarcinoma is associated with histopathological features, including invasion of the rectal wall or perirectal fat and lymph node involvement, a number of patients experience recurrence despite undergoing potentially curative procedures and early pathological staging (12-13). It has been proposed that genetic alterations acquired during tumor development may predict prognosis (14). For example, the expression of the $\mathrm{p} 53$ protein has been found to predict a worse prognosis in rectal adenocarcinoma (14). Similarly to SCC of the esophagus, the current study identified positive AC3-33 expression in rectal adenocarcinoma, but negative expression in cancer-adjacent normal rectal tissue.

In conclusion, the differential expression of AC3-33 may be significant in the development and progression of rectal adenocarcinoma and esophagal SCC, and may be used as a prognostic indicator. However, the mechanism of AC3-33 function appears to be complex and further investigations are required to elucidate the role and molecular mechanisms of AC3-33 in the development and progression of rectal adenocarcinoma and esophagal SCC.

\section{Acknowledgements}

This study was supported by grants from the National Natural Science Foundation of China (grant nos. 81072093; 30671092; 
81302323), the Natural Science Foundation of Hebei Province (grant nos. C2009001260; C2013209024; C2014209140), the General Higher Education Young Talents Program of Hebei Province (BJ2014027), and the Science and Technology Support Program of Tangshan City (grant no. 14120208a).

\section{References}

1. Zhang X, Ma X, Xue Y, et al: Prokaryotic expression and characterization of human AC3-33 protein. Front Biosci (Elite Ed) 2: $1134-1142,2010$

2. Angel P and Karin M: The role of Jun, Fos and the AP-1 complex in cell-proliferation and transformation. Biochim Biophys Acta 1072: 129-157, 1991.

3. Hao D, Gao P, Liu P, et al: AC3-33, a novel secretory protein, inhibits Elk1 transcriptional activity via ERK pathway. Mol Biol Rep 38: 1375-1382, 2011.

4. Liu P, Deng WW, Gao P, et al: Molecular cloning and preliminary function study of a novel human gene AC3-33 related to suppress AP-1 activity. Yi Chuan 30: 575-582, 2008. (In Chinese).

5. Bollschweiler E and Hölscher AH: Carcinoma of the esophagus-actual epidemiology in Germany. Onkologie 24: 180-184, 2001. (In German).

6. Suita S,Zaizen Y,Kaneko M, et al: What is the benefit of aggressive chemotherapy for advanced neuroblastoma with N-myc amplification? A report from the Japanese study group for the treatment of advanced neuroblastoma. J Pediatr Surg 29: 746-750, 1994.
7. Kitagawa Y, Ueda M, Ando N, Shinozawa Y, Shimizu N and Abe O: Significance of int-2/hst-1 coamplification as a prognostic factor in patients with esophageal squamous carcinoma. Cancer Res 51: 1504-1508, 1991.

8. Shinozaki H, Ozawa S, Ando N, et al: Cyclin D1 amplification as a new predictive classification for squamous cell carcinoma of the esophagus, adding gene information. Clin Cancer Res 2: 1155-1161, 1996.

9. Yamasaki M, Miyata H, Fujiwara Y, et al: p53 genotype predicts response to chemotherapy in patients with squamous cell carcinoma of the esophagus. Ann Surg Oncol 17: 634-642, 2010.

10. National Cancer Institute: Colon Cancer Treatment (PDQ $®)$ http://www.cancer.gov/cancertopics/pdq/treatment/colon/ Patient/page1/AllPages. Accessed, 29 June 2014.

11. Comprehensive molecular characterization of human colon and rectal cancer. Nature 487: 330-337, 2012.

12. Olson RM, Perencevich NP, Malcolm AW, Chaffey JT and Wilson RE: Patterns of recurrence following curative resection of adenocarcinoma of the colon and rectum. Cancer 45: 2969-2974, 1980.

13. Ratto C, Sofo L, Ippoliti M, Merico M, Doglietto GB and Crucitti F: Prognostic factors in colorectal cancer. Literature review for clinical application. Dis Colon Rectum 41: 1033-1049, 1998.

14. Jurach MT, Meurer L and Moreira LF: Expression of the p53 protein and clinical and pathologic correlation in adenocarcinoma of the rectum. Arq Gastroenterol. 43: 9-14, 2016. 